\title{
Does the Presence of Renal Vascular Variation in the Renal Allograft Determine the Outcome of Renal Transplantation? Experience from the National Kidney Transplantation Center, Ethiopia
}

Habtamu Wondmagegn

Arba Minch University

Abinet Gebremickael ( $\square$ abinetgebremickael@gmail.com )

Arba Minch University

Mahteme Bekele

Saint Paul Hospital Millennium Medical College

Mala George

Arba Minch University

Teshale Fikadu

Arba Minch University

Tadiwos Hailu

Arba Minch University

Tsegazeab Ayele

Arba Minch University

Research Article

Keywords: Renal transplantation, Variant renal vasculature, renal allograft, Graft survival

Posted Date: August 18th, 2021

DOI: https://doi.org/10.21203/rs.3.rs-720260/v1

License: (c) (1) This work is licensed under a Creative Commons Attribution 4.0 International License.

Read Full License

Version of Record: A version of this preprint was published at Clinical Audit on February 1st, 2022. See the published version at https://doi.org/10.2147/CA.S347743. 


\section{Abstract}

Background: Renal transplantation is the treatment of choice for people who suffer from end stage renal disease. Renal vascular anatomy is known for presenting a wide range of variations. Kidneys with variant renal vascular anatomy when used as a graft appear to be a potential risk factor that could impair the outcome of kidney transplantation. Information on renal vascular variations and its implication in the surgical outcome of renal transplantation has not been well studied. Hence, the present study was aimed to evaluate the outcomes of transplantation of renal allografts with variant renal vasculature as compared to allografts without renal vascular variation in the national kidney transplantation center of Ethiopia.

Methods: A health institution based cross-sectional study was conducted. A retrospective review of the medical records of kidney recipients was performed. A total of 120 renal transplant recipient's medical records were evaluated. Chi-square test and Independent $t$ test was used to compare the surgical outcomes of renal transplantation. Graft survival was expressed using Kaplan-Meier curves, and was compared using the log-rank test. $P$ values less than 0.05 was considered as statistically significant.

Result: Evaluation of the renal transplant outcomes did not have shown a significant difference in the postoperative complication rate, rate of delayed graft function (DGF), creatinine clearance levels at 1,6 , or 12 months postoperatively, and 1-year graft survival among recipients of allografts with and without renal vascular variations. However, operation time and the length of hospital stay were significantly longer among recipients of allografts with variant vasculature.

Conclusion: No significant difference was noted in the outcomes of transplantation of renal allografts with and without vascular variations. Hence, renal allografts with vascular variations are safe to be recruited for transplantation as to this study.

\section{Background}

End-stage renal disease (ESRD) is diagnosed when the patient has reached Glomerular filtration rate (GFR) of less than $15 \mathrm{~mL} / \mathrm{min}$ (1). Renal replacement therapy (RRT) is required for ESRD. Hemodialysis, peritoneal dialysis, and transplantation are the three types of RRT. ESRD patients can be successfully treated with hemodialysis or peritoneal dialysis, but kidney transplantation is by far the best therapeutic choice for the vast majority of ESRD patients $(2,3)$. The operation necessitates extensive preoperative preparation and careful kidney selection. The site for transplanting a kidney is in the iliac fossa of the greater pelvis. The renal artery and vein are joined to the external iliac artery and vein, respectively, and the ureter is sutured into the urinary bladder (4).

Kidneys with variant vasculature are prevalent in the general population (between $18 \%$ and $50 \%$ ). Worldwide, more than 100,000 kidney transplantations are performed each year (5). Owning the scarcity of donor kidney and the rising frequency of end-stage renal disease (ESRD), there is a global trend toward approving the so-called extended criteria kidney donors. Transplantation of renal allograft with vascular 
variations necessitates a sophisticated vascular reconstruction and anastomosis. Because renal vascular variations in kidney donors are linked to greater surgical complication rates in both the donor and recipient, recruiting renal allograft with variant vasculature for transplantation is considered as an expanded criterion (6).

Some studies have linked the extensive dissection and back-table reconstruction to an elevated risk that could compromise the renal transplantation outcome $(7,8)$. Besides, transplanting kidneys with arterial and venous variations are thought to have several disadvantages, such as prolonged warm ischemia duration; an increased incidence of acute tubular necrosis, which can increase the risk of acute rejection episodes, prolonged hospitalization; and poorer graft function (7). Consequently, even though kidneys with vascular variation are common in the general population, the kidney with simple vascular anatomy (ideally one artery, one vein) is often chosen for transplantation since the technical components of the process are usually completed without difficulties (9-11). However, there is a dearth of literature that has assessed and reported the outcomes of transplantation of a renal allograft with a variant vasculature in Ethiopia.

In Ethiopia, the first kidney transplantation took place in 2015 (4). Since then, the practice of kidney transplantation in the country has shown steady expansion and progress (4). Given the rising number of kidney transplantation procedures, and being the variations of renal vascular are is common in the general population, renal allografts with variant vasculature are to be reputed for transplantation. Otherwise, significant number of kidney donors will not be entitled for donating a kidney only for having a variant renal vasculature; this may worse the shortage of a kidney for transplantation. Hence, it has become important at this point to evaluate the outcome of transplantation of a renal allograft with a variant vasculature. The finding of the present study will advance the available information on the association between renal vascular anatomy and its transplantation outcomes.

\section{Materials And Methods}

A health institution based cross-sectional study with retrospective record review was conducted at the national kidney transplantation center (NKTC), St. Paul's Hospital Millennium Medical College (SPHMMC), located at Addis Ababa, Ethiopia. The study was conducted on the kidney recipients who underwent kidney transplantation from a period of commencement of the first renal transplantation in Ethiopia on September 2015 to August 2020 in the center. The total number of transplantation performed in the institution from 2015 to 2020 was 142. And 22 of them had incomplete relevant information in their medical record; hence, this study was carried out on a total of 120 recipients who underwent kidney transplantation in the transplantation center.

All the relevant data were collected from the patient's medical record by using a checklist. The checklist contains parts about socio-demographic, anatomical characteristics of renal vasculature, and clinical characteristics of recipients and outcome measurements of renal transplantation. To assure the data quality, data collection tool was prepared after intensive review of relevant literatures and similar studies. 
Recipient's demography (Age, Sex, Relationship with donor), the renal vascular variations of the transplanted renal allografts (Single artery, Presences of accessory renal artery, Presence of early branching main renal artery, Unusual branching of renal artery, Precaval renal artery, Single vein, Presence of accessory renal vein, Presence of retro-aortic left renal vein, Presence of circum-aortic left renal vein, Presences of late confluence of renal vein), and Clinical factors (BMI $\left(\mathrm{kg} / \mathrm{m}^{2}\right.$, Preoperative serum creatinine, Duration on hemodialysis) were considered as determinant variables of the transplantation outcome in the present study. All renal recipients were categorized into two based on the presence of vascular variations in the allograft and the data were compared with respect to patient demographics, operative characteristics, postoperative course and complications.

\section{Statistical Analysis}

The collected data was coded, cleaned, and entered into Epi-data version 4.4 and exported to SPSS version 25 for analysis. Variables were described as frequency, percentages, mean, and standard deviation (SD). Chi-square test was used for comparison of categorical variables whereas Independent ttest for the comparison of continuous variables. Graft survival was expressed using Kaplan-Meier curves, and was compared using the log-rank test. Statistical significance was declared at $P<0.05$. Results were presented by using tables, figures, and texts.

\section{Results}

\section{Baseline characteristics of Kidney Transplantation recipients}

Among a total of 120 recipients, $86(71.6 \%)$ were males with a mean age of 33.3 years (SD \pm 11.41$) .34$ $(28.3 \%)$ recipients received renal allografts with renal vascular variations. Of the 34 recipients who received kidney with variant vasculature, $28(82.4 \%)$ patients received an allograft with renal arterial variation, and $6(17.6 \%)$ patients received an allograft with renal venous variations. With regard to age, sex, and $B M I$, no significant difference $(P>0.05)$ was noted between groups of patients who received renal allograft with anatomically variant renal vasculature and without (Table 1). 
Table 1

Baseline characteristics of kidney transplantation recipients at NKTC, SPHMMC, 2021.

\begin{tabular}{|c|c|c|c|c|c|c|}
\hline \multicolumn{2}{|c|}{ Recipient characteristics } & $\begin{array}{l}\text { All } \\
\text { recipients } \\
(n=120)\end{array}$ & \multicolumn{2}{|c|}{$\begin{array}{l}\text { Recipients receiving } \\
\text { allograft with normal } \\
\text { vascular anatomy } \\
(n=86)\end{array}$} & \multirow[t]{2}{*}{$\begin{array}{l}\text { Recipients receiving } \\
\text { allograft with } \\
\text { variant } \\
\text { vascular anatomy } \\
(\mathrm{n}=34) \\
24(27.9)\end{array}$} & \multirow[t]{2}{*}{$\begin{array}{r}\text { P-value } \\
\\
0.869\end{array}$} \\
\hline \multirow[t]{2}{*}{ Sex } & Male & \multicolumn{2}{|c|}{$86(71.7$} & $62(72.1)$ & & \\
\hline & Female & \multicolumn{2}{|c|}{$34(28.3)$} & $24(70.6)$ & $10(29.4)$ & \\
\hline \multicolumn{2}{|c|}{ Age $($ mean $\pm S D)$} & $\begin{array}{l}33.26 \pm \\
11.1\end{array}$ & \multicolumn{2}{|c|}{$32.9 \pm 10.8$} & $34.1 \pm 11.8$ & 0.608 \\
\hline \multicolumn{2}{|c|}{$\mathrm{BMI}($ mean $\pm \mathrm{SD})$} & $23.8 \pm 2.8$ & \multicolumn{2}{|c|}{$23.5 \pm 2.8$} & $24.5 \pm 2.8$ & 0.087 \\
\hline \multirow[t]{2}{*}{ Relation } & Blood related & 105 & \multicolumn{2}{|l|}{76} & 29 & 0.646 \\
\hline & Spouse & 15 & \multicolumn{2}{|l|}{10} & 5 & \\
\hline \multicolumn{2}{|c|}{$\begin{array}{l}\text { Preoperative serum } \\
\text { Creatinine (mean } \pm \text { SD) }\end{array}$} & $12.4 \pm 1.4$ & \multicolumn{2}{|c|}{$12.6 \pm 1.5$} & $12.3 \pm 1.3$ & 0.199 \\
\hline \multicolumn{2}{|c|}{$\begin{array}{l}\text { Duration on } \\
\text { hemodialysis (months) } \\
\text { (mean } \pm \text { SD) }\end{array}$} & $19.3 \pm 3$ & \multicolumn{2}{|c|}{$19.4 \pm 3.2$} & $18.919 .4 \pm 2.5$ & 0.286 \\
\hline
\end{tabular}

\section{Operative parameters and allograft outcomes of recipients}

Operative time and length of hospital stay were significantly longer $(P<0.05)$ among recipients of allografts with variant renal vasculature as compared to recipients of allografts without variant renal vasculature. Graft function measured by serum creatinine values at postoperative week 1 , first month, six month, and one year were not significantly different $(P>0.05)$ between recipients of allografts with variant renal vasculature and without variant renal vasculature (Fig. 1). Diuresis of the transplanted kidney on the operation table was achieved in $95 \%$ of the transplantations and did not significantly differed $(P>0.05)$ based on the renal vascular anatomy; that is, between groups who received allografts with and without variant renal vasculature. Only two of the patients who received allografts without vascular variation and, one patient who received an allograft with vascular variation needed dialysis during the first postoperative week, this is nearly similar rate between groups. Although not significant ( $P$ $>0.05$ ), post-operative complications were more frequently reported in patients who received grafts with variant renal vascular anatomy than without. Re-admission and re-operation rates were similar between the groups (Table 2). 
Table 2

Intra and post-operative outcome of transplantation of renal allografts with and without variant vasculature at NKTC, SPHMMC, 2021.

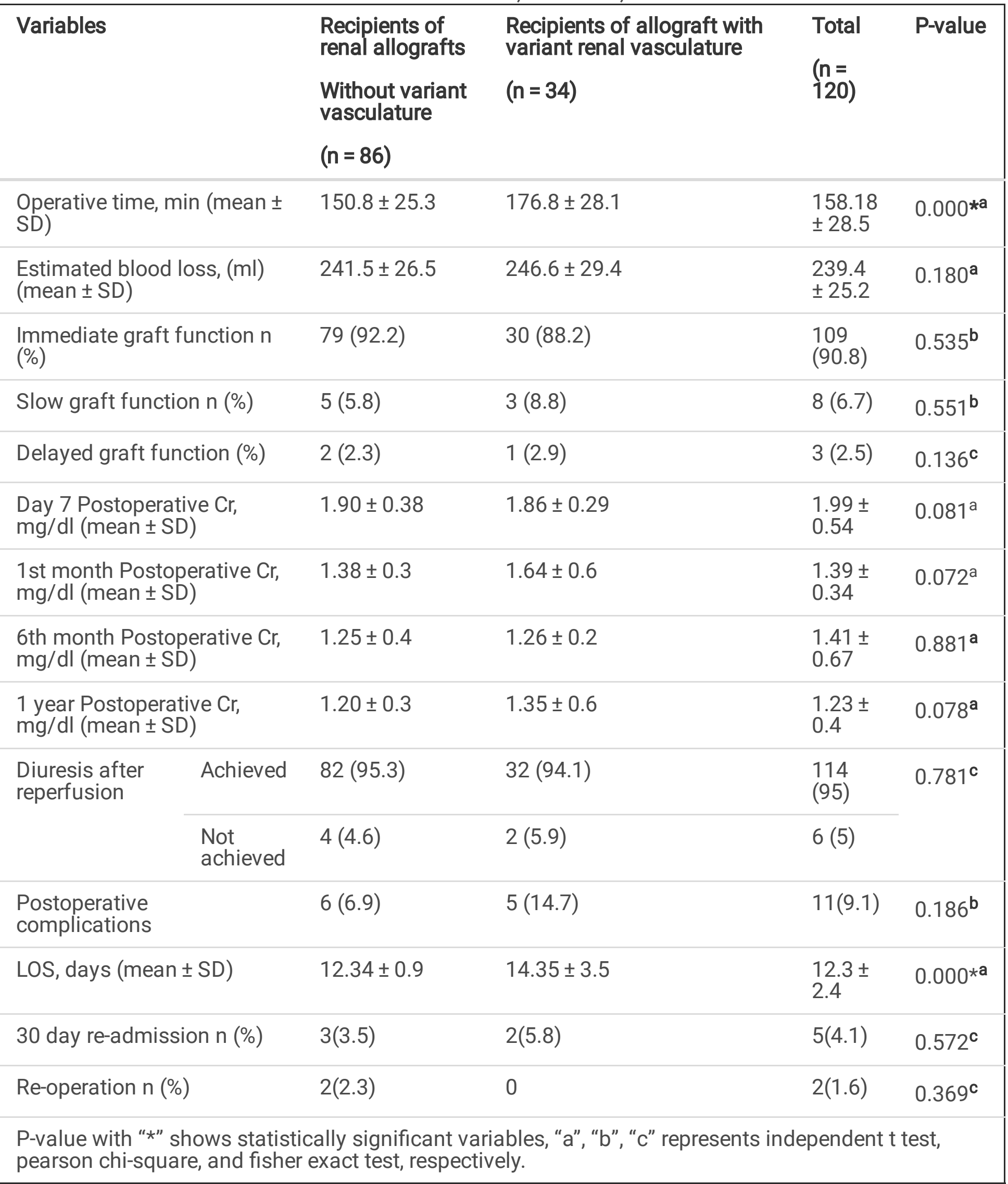


Postoperative graft survival was analyzed at 1week, 1 month, 6month and 1 year (Fig. 2). The 1-year graft survival for 86 patients who received grafts without vascular variations was 95.4\%, and that for the 34 patients who received grafts with vascular variations was $91.2 \%$. The result exhibited that the variation of renal vascular anatomy is not a determinant for the graft survival $(P=0.378)$.

\section{Discussion}

Evaluation of the renal transplant outcomes did not have shown a significant difference in the postoperative complication rate, rate of delayed graft function (DGF), serum creatinine levels at 1,6 , or 12 months postoperatively, and 1-year graft survival among recipients of allografts with and without renal vascular variations. However, operation time and the length of hospital stay were significantly longer among recipients of allografts with variant vasculature.

In the present study 34 (28.3\%) renal transplantations were performed by using renal allografts with variant vasculature. All the renal allografts (100\%) that have been used for the transplantations carried out in the center were left kidneys. The practice of selecting left-sided grafts is not uncommon and has been reported in several studies (12-14). Furthermore, previous studies have commented on an increased risk of early graft failure with transplanting right-sided renal allografts (15). In contrast, some centers have used a large number of right-sided renal allografts and reported no significant difference in graft function (16). The preference of left- sided renal allografts is often due to the longer left renal vein, which makes vascular anastomosis technically easier and also been shown to decrease operating time (16).

Post-operative serum creatinine level is an important measure of the outcome of renal transplantation. The present study has shown the post-operative serum creatinine level values recorded at postoperative week 1, first month, sixth month, and one year were not significantly differed between recipients of allografts with and without variant renal vasculature. This finding supports the reports of Ashraf et al. and Basaran et al. who also declared no significant difference on the serum creatinine values at one, two or five years between recipients of allografts with and without renal vascular variations $(13,17)$.

A comparative higher rate of postoperative complication rate was registered (14.7\%) among recipients of allografts with variant renal vasculature, however the difference was statistically insignificant compared to recipients of allografts without variant renal vasculature (6.9\%). Similar to this finding, a study by Hsu et al. also did not see a difference in intra- and postoperative complication rates in a series comparing 277 allograft with normal vascular anatomy and 76 variant vasculature (18). However, Carter et al found a small increase in ureteral complications among recipients with vascular variant graft (19).

Diuresis of the transplanted kidney on the operation table is another important parameter of successful renal transplantation. In the current study, $95 \%$ of the transplanted allografts could have produced urine immediately after reperfusion. There was no significant difference noted between the groups on the rate of diuresis after reperfusion. In line with this finding, Lafrancha et al. reported no significant differences in the occurrence of diuresis of the transplanted kidney on the operation table $(p=0.735)$. Moreover, a study by Asuri krishina et al. showed the mean urine output postoperative day 1 and postoperative day 7 were 
not significantly different between recipients of complex vascular allografts and simple vascular allografts (20). Similarly, Kok et al, reported urine production within one hour of reperfusion was $91 \%$ for single artery allograft recipients and $92 \%$ for multiple artery allograft recipients $(p=0.639)(21)$.

In the present study, operation time and the length of hospital stay were significantly longer among recipients of allografts with variant vasculature. In contrast to this finding, several other studies have reported that operation time and length of hospital stay were shorter and not significantly different among recipients of allografts with and without vascular variation $(12,20,22)$. The longer operation time reported in this study is may be due to the open approach of the donor nephrectomy procedure employed in the transplantation center as this procedure is performed simultaneously with the transplantation surgery. Open donor nephrectomy takes longer operation time as compared to laparoscopic nephrectomy (14). Despite a statistically significant difference noted in the operation time and length of hospital stay, the clinical impact of these parameters is limited (12). Estimated blood loss, 30 day readmission and reoperation rates were not significantly different with the renal vascular variations of the renal allograft, and this finding is supported by many other authors (20-22).

The 1-year graft survival rate was nearly unaffected by the renal vascular anatomy in this study, and was greater than $90 \%$ in both groups. The grafts without vascular variations had better graft survival at different points of measurement, but the difference was not statistically significant $(p=0.378)$. This finding is consistent with graft survival rates reported in various previous studies. The study by Hsu et al. analyzed 76 recipients of variant vascular grafts and reported a 1-year graft survival rate of $93.4 \%$ (18). Similarly, Desai et al. retrospectively reviewed 27 recipients of renal allograft with multiple renal artery and reported the overall graft survival rate of $92.6 \%(23)$.

\section{Conclusion}

Transplantation of renal allografts with and without renal vascular variations has comparable outcomes as to the present study. Although operation time and length of hospital stay were significantly different between the groups, their clinical relevance is minimal. Hence, renal allografts with vascular variations are safe to be recruited for transplantation, and the entitlement of such allografts will increase the availability of kidneys for renal transplantations.

\section{Abbreviations}




\begin{tabular}{ll} 
AMU & Arba Minch University \\
BMI & Body mass index \\
Cr & Creatinine \\
DGF & Delayed graft function \\
\hline ESRD & End-stage renal disease \\
\hline LOS & Length of stay \\
\hline NKTC & National kidney transplantation center \\
\hline SD & Standard deviation \\
SPHMMC & St. Paul's hospital millennium medical college \\
\hline SPSS & Statistical Package for the Social Sciences
\end{tabular}

\section{Declarations}

\section{Ethics approval and consent to participate}

This study was carried out after obtaining ethical approval from Arba Minch University institutional research ethics review board/IRB (Ref.no: IRB/552/12; Issue date: 26/11/2020). As the study was retrospective review of medical records, the need for consent was waived by the ethics committee. No personal identifiers were used in the study.

\section{Consent for publication}

Not applicable

\section{Availability of data and materials}

All the datasets used and/or analysed during the current study are available from the corresponding author on reasonable request

\section{Competing interests}

The authors declare that they have no competing interests

\section{Funding}

The current study was monetarily supported by AMU. 


\section{Authors' contributions}

HW contributed to inception of the project, data collection, analysis and draft manuscript writing. AG contributed to project design and manuscript writing. MB interpreted the patient data. GM contributed to project design and manuscript reviewing. TF contributed to project design and analysis. TH contributed to clinical interpretation and manuscript reviewing. TA contributed to data collection and drafting manuscript. All authors have read and approved the final manuscript.

\section{ACKNOWLEDGMENTS}

Not applicable

\section{References}

1. Fauci A, Braunwald E, Kasper D. Harrison Principles of Internal Medicine 18th edn ed. New York NY: McGraw Hill Medical; 2015.

2. Meier-Kriesche HU, Schold JD, Srinivas TR, Reed A, Kaplan B. Kidney transplantation halts cardiovascular disease progression in patients with end-stage renal disease. American Journal of Transplantation. 2004;4(10):1662-8.

3. Davis CL, Delmonico FL. Living-donor kidney transplantation: a review of the current practices for the live donor. Journal of the American Society of Nephrology. 2005;16(7):2098-110.

4. Getachew S. Medical outcome of renal allograft donors at National kidney transplant center-Saint Paul's Hospital Millennium Medical College, Addis Ababa, Ethiopia. Ethiopian Medical Journal. 2020.

5. Global Observatory on Donation and Transplantation: Kidney Transplants. Available at:http://wwwtransplantobservatoryorg/countkidney/. 2019.

6. Ahmadi AR, Lafranca JA, Claessens LA, Imamdi RM, IJzermans JN, Betjes MG, et al. Shifting paradigms in eligibility criteria for live kidney donation: a systematic review. Kidney International. 2015;87(1):31-45.

7. Zorgdrager M, Krikke C, Hofker SH, Leuvenink H, Pol RA. Multiple renal arteries in kidney transplantation: a systematic review and meta-analysis. Ann Transplant. 2016;21(469):10.12659.

8. Nogueira JM HA, Jacobs SC, Weir MR, Hurley HA, Al-Qudah HS, et al.: .. The detrimental effect of poor early graft function after laparoscopic live donor nephrectomy on graft outcomes. Am J Transplant. 2009;; 9: 337-47.

9. Famurewa O, Asaleye C, Ibitoye B, Ayoola O, Aderibigbe A, Badmus T. Variations of renal vascular anatomy in a nigerian population: A computerized tomography study. Nigerian journal of clinical practice. 2018;21(7):840-6.

10. Hasan MASMA. RENAL ARTERY MORPHOLOGY AND ANATOMICAL VARIATIONS AMONG SUDANESE SUBJECTS Anatomy Journal of Africa. 2018;7(1):1103-12 
11. Raman SS, Pojchamarnwiputh S, Muangsomboon K, Schulam PG, Gritsch HA, Lu DS. Surgically relevant normal and variant renal parenchymal and vascular anatomy in preoperative 16-MDCT evaluation of potential laparoscopic renal donors. American Journal of Roentgenology. 2007;188(1):105-14.

12. Cooper M, Kramer A, Nogueira JM, Phelan M. Recipient outcomes of dual and multiple renal arteries following 1000 consecutive laparoscopic donor nephrectomies at a single institution. Clinical transplantation. 2013;27(2):261-6.

13. Ashraf HS, Hussain I, Siddiqui AA, Ibrahim MN, Khan MU. The outcome of living related kidney transplantation with multiple renal arteries. Saudi Journal of Kidney Diseases and Transplantation. 2013;24(3):615.

14. Arpalı E, Karataş C, Akyollu B, Yaprak D, Günaydın B, Koçak B. Hand-assisted laparoscopic donor nephrectomy in kidneys with multiple renal arteries versus a single renal artery: An analysis of vascular complications from 1,350 cases. Turkish Journal of Urology. 2020.

15. Hsu JW, Reese PP, Naji A, Levine MH, Abt PL. Increased early graft failure in right-sided living donor nephrectomy. Transplantation. 2011;91(1):108-14.

16. Broudeur L, Karam G, Chelghaf I, De Vergie S, Rigaud J, Verbe MP, et al. Feasibility and safety of laparoscopic living donor nephrectomy in case of right kidney and multiple-renal artery kidney: a systematic review of the literature. World Journal of Urology. 2019:1-9.

17. Başaran Ö, Moray G, Emiroğlu R, Alevli F, Haberal M, editors. Graft and patient outcomes among recipients of renal grafts with multiple arteries. Transplantation proceedings; 2004: Elsevier.

18. Hsu TH, Su L, Ratner LE, Trock BJ, Kavoussi LR. Impact of renal artery multiplicity on outcomes of renal donors and recipients in laparoscopic donor nephrectomy. Urology. 2003;61(2):323-7.

19. Carter JT, Freise CE, McTaggart RA, Mahanty HD, Kang SM, Chan SH, et al. Laparoscopic procurement of kidneys with multiple renal arteries is associated with increased ureteral complications in the recipient. American journal of transplantation. 2005;5(6):1312-8.

20. Asuri Krishna UM, Mayank Jain, Om Prakash, Subodh Kumar, V Seenu et al.. Outcomes of Complex V/S Simple Vascular Anatomy Grafts Following Living Donor Renal Transplant-Experiance from a Tertiary Care Center. Clinical Nephrology and Renal Care. 2020;6(2):4-6.

21. Kok NF, Dols LF, Hunink MGM, Alwayn IP, Tran KT, Weimar W, et al. Complex vascular anatomy in live kidney donation: imaging and consequences for clinical outcome. Transplantation. 2008;85(12):1760-5.

22. Lafranca JA, van Bruggen M, Kimenai HJ, Tran TC, Terkivatan T, Betjes MG, et al. Vascular multiplicity should not be a contra-indication for live kidney donation and transplantation. PloS one. 2016;11(4):e0153460.

23. Desai MR, Ganpule AP, Gupta R, Thimmegowda M. Outcome of renal transplantation with multiple versus single renal arteries after laparoscopic live donor nephrectomy: a comparative study. Urology. 2007;69(5):824-7. 
Figures

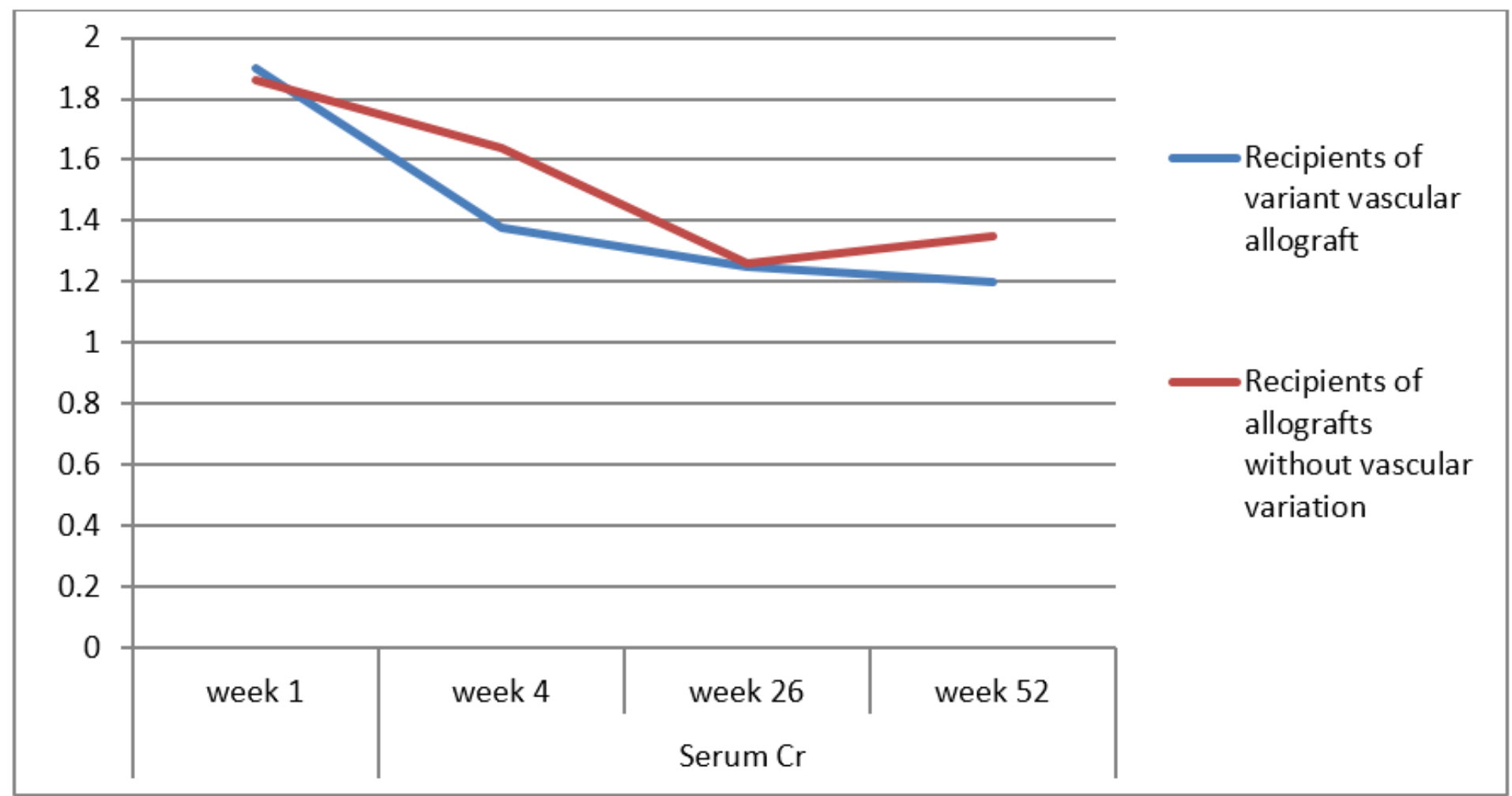

\section{Figure 1}

A line graph showing the mean post-operative serum creatinine level for recipients of allografts with and without vascular variations at NKTC, SPHMMC, 2021. 


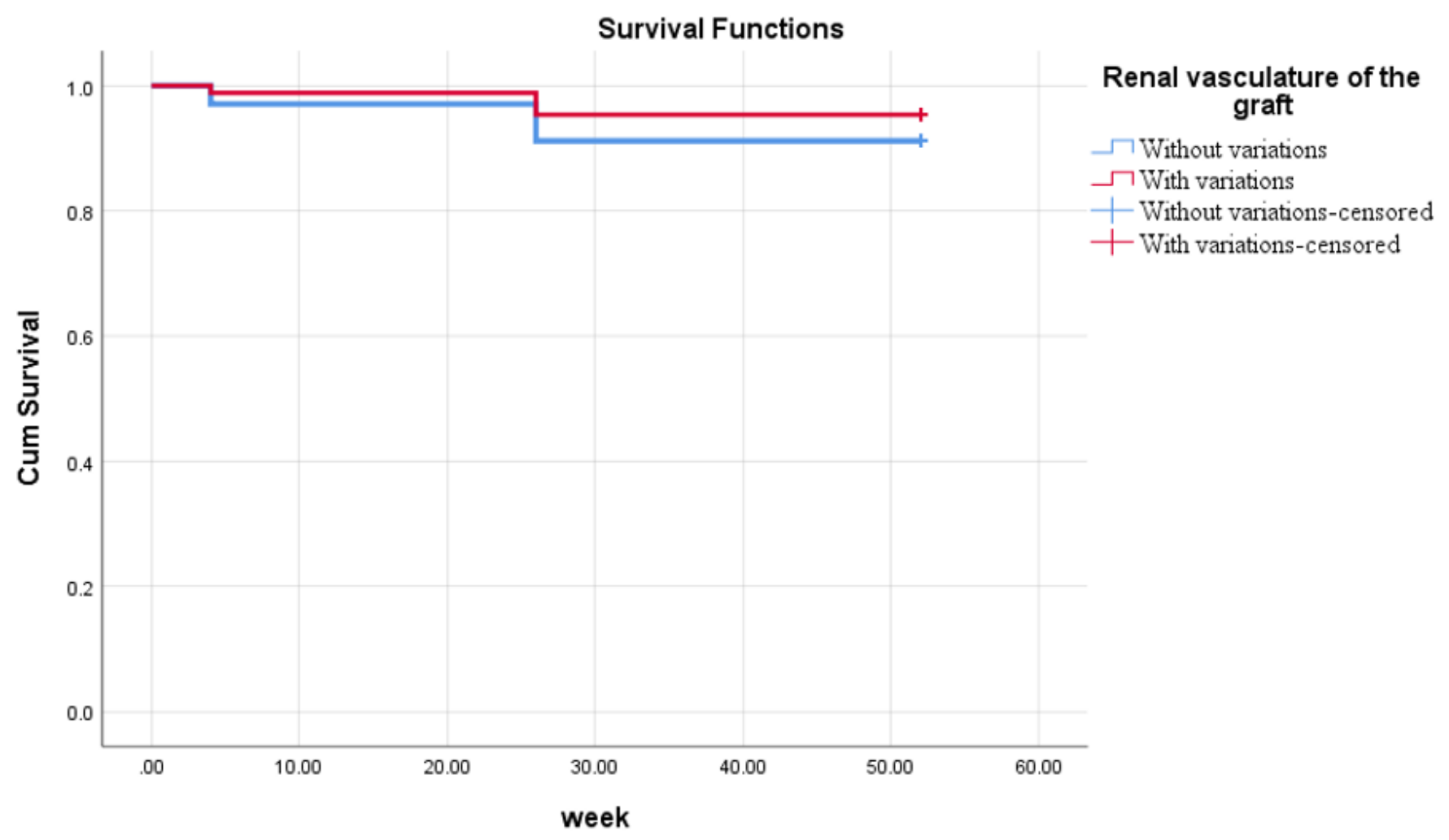

Figure 2

Kaplan-Meier analysis of estimated graft survival based on renal vascular anatomy of the graft. ( $P=0.378$ using the logrank test (Mantel-Cox). 